\title{
Oral Health Status of Disabled Individuals Attending Special Schools
}

\author{
Ceyhan Altun ${ }^{a}$ \\ Gunseli Guven ${ }^{a}$ \\ Ozlem Marti Akgun ${ }^{b}$ \\ Meltem Derya Akkurt ${ }^{b}$ \\ Feridun Basak ${ }^{a}$ \\ Erman Akbulut ${ }^{c}$
}

\begin{abstract}
Objectives: The purpose of this study was to determine the prevalence of the dmft-DMFT indexes and the oral hygiene status of 136 individuals attending a special school for the disabled.

Methods: Participants were grouped according to disability [Mental Retardation (MR), Cerebral Palsy (CP), Autistic Disorder (AD), Down Syndrome (DS), Other (OTH)] and age [2-6 years (n=24), 7-12 years (50 children) and 13+ years (62 children]. Caries examinations were carried out in accordance with WHO criteria and oral cleanliness was evaluated by visually assessing the presence of plaque on teeth.

Results: The age range of patients was 2-26 years (mean age: $11.89 \pm 5.19$ years). Mean dmft and DMFT scores by age group were as follows: $2-6$ years: $d m f t=2.04 \pm 2.24 ; 7-12$ years: $d m f t=2.24 \pm 2.60$, $\mathrm{DMFT}=0.98 \pm 2.58$; $13+$ years: $\mathrm{DMFT}=2.68 \pm 2.91$. Overall, $15.4 \%$ of children had no caries or fillings. While dmft and DMFT levels ( $P>$.05) did not vary significantly by type of disability, oral cleanliness did. Children with autism were observed to maintain the best oral hygiene and those with mental retardation (MR), the poorest.

Conclusions: It is important for the dentist to concentrate on a preventive approach and provide proper dental education to parents of disabled individuals. Among the children with disabilities, more attention should be paid to the oral hygiene of MR group. (Eur J Dent 2010;4:361-366)
\end{abstract}

Key words: Disabled individual; Oral health; Caries; Oral plaque.

a Associate Professor, Department of Pediatric Dentistry, Center of Dental Sciences, Gulhane Medical Academy, Ankara, Turkey.

b Assistant, Department of Pediatric Dentistry, Center of Dental Sciences, Gulhane Medical Academy, Ankara, Turkey.

Professor, Department of Pediatric Dentistry, Center of Dental Sciences, Gulhane Medical Academy, Ankara, Turkey.

- Corresponding author: Ceyhan Altun Department of Pediatric Dentistry, Center of Dental Science Gulhane Military Medical Academy, Etlik, Ankara, Turkey.

Phone: +90 (312) 3046045 Fax: +90 (312) 3046020

E-mail: ceyhanaltundayahoo.com

\section{INTRODUCTION}

The American Health Association defines a child with disability as a child, who, for various reasons, cannot fully make use of all his or her physical, mental and social abilities ${ }^{1}$ - in other words, a child who cannot play, learn, or do things that other children his or her age can. In general, disabilities in children may be present individually or as a set of multiple physical, developmental, cognitive and/or affective disabilities. According to World Health Organization estimates, individuals with disabilities comprise $10 \%$ of the population in developed countries and $12 \%$ in developing coun- 
tries. ${ }^{2}$ In Turkey, there are an estimated 9 million children aged $0-18$ years who have disabilities and have special needs. This amounts to one member with disability per 7-8 households. ${ }^{3}$ Because of their special care needs, daily care of children with disabilities is different from that of children with normal abilities, who can usually manage their own oral health. In contrast, children with disabilities may be partially or wholly dependent on someone else to perform their daily care activities, and this situation may cause difficulties for the families of these children. ${ }^{4}$

Oral disease is a major health problem for adults with disabilities, ${ }^{5}$ who have a higher prevalence and severity of oral disease when compared to the general population. ${ }^{6}$ High rates of dental caries, missing teeth, periodontal disease, prolonged retention of primary teeth, misaligned or supernumerary teeth and malocclusion are all indicators of poor oral health in adults with disabilities. ${ }^{7}$ Poor oral health has negative impact on nutrition, digestion, the ability to chew and enjoy food, facial shape and speech. ${ }^{8}$ Under-diagnosis and differential oral health treatment contribute to the poor oral health of adults with disabilities. ${ }^{9,10}$

The purpose of this study was to determine the prevalence of dental caries (dmft and DMFT indexes) and the oral hygiene status of 136 children and young adults attending a special school for the disabled.

\section{MATERIALS AND METHODS}

A total of 136 individuals with disabilities between the ages of 2-26 attending a special education program at the Gulhane Medical School participated in the study. Informed consent was obtained from the participants' parents, who were provided with detailed information on the study protocol. Both the consent form and the research protocol were approved by the Institutional Human Subject Review Committee. Dental examinations took place at the school, with participants seated on an ordinary chair and illumination provided by an ordinary fluorescent lamp. Participants did not have their teeth brushed or professionally cleaned prior to the examination. Participants were divided into five groups according to type of disability, as follows: 1. Mental Retardation (MR) (n=43); 2. Cerebral Palsy (CP) ( $n=29) ; 3$. Autistic Disorder (AD) $(n=22) ; 4$. Down Syndrome (DS) $(n=16) ; 5$. Other
(OTH) (Hydrocephaly, Hemiplegia, Spinal Muscular Atrophy, Joubert Syndrome, Dysmorphic Syndrome, West Syndrome, Rett Syndrome, Goldenhar Syndrome $(n=26)$. Participants were also divided into three groups according to their age, as follows: 1 . Age $2-6$ years $(n=24) ; 2$. Age $7-12$ years $(n=50) ; 3$. Age $13+$ years $(n=62)$. Dental caries examinations were carried out using a mirror and explorer in accordance with World Health Organization criteria and methods. ${ }^{11}$ The total number of decayed, missing and filled primary and permanent teeth (dmft, DMFT) were recorded for each patient. No radiographic examination was undertaken. Oral cleanliness was evaluated by visually assessing the buccal and lingual surfaces of the upper and lower incisors and canines for the presence of plaque using the Silness \& Lö $\mathrm{e}^{12}$ index, as follows: (0) no visible plaque; (1) visible plaque; (2) an abundant amount of visible plaque.

Data was recorded in an Excel table using patient names and identification numbers. Statistical analysis was carried out using the SPSS software program. Chi-square test was used to determine significant differences in data $(P<.05)$.

\section{RESULTS}

Of the 136 participants in the study, the majority $(67.6 \%)$ were male $(n=92)$. Patient ages ranged from $2-26$ years (mean: $11.89 \pm 5.19$ years). Table 1 shows the distribution of subjects by age, sex and type of disability, and Table 2 shows the distribution of dmft-DMFT scores by age group and sex. The overall mean dmft and DMFT scores for participants were $1.18 \pm 2.11$ and $1.58 \pm 2.72$, respectively. The dmft and DMFT indexes of the different disabled groups did not vary significantly by age group ( $P>$.05).

Table 3 shows the distributions of $\mathrm{dmft}$ and DMFT scores by disability. The Down Syndrome

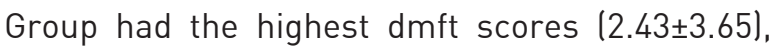
whereas the Mental Retardation Group had the highest DMFT scores. When analyzed by age group as well as disability type, the other group had the

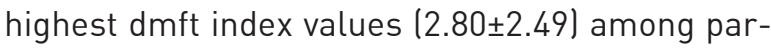
ticipants aged 2-6, the Down Syndrome Group had

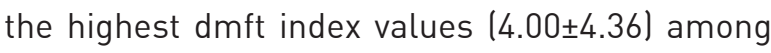
those aged 7-12, the other group had the highest DMFT index values $(2.23 \pm 4.46)$ among those aged 7-12, and the Down Syndrome Group had the highest DMFT index values $(3.00 \pm 2.65)$ among those 
aged 13+ (Table 4). Differences between dmftDMFT indexes were not statistically significant (P>.05).

The distribution of plaque index scores among participants is shown in Table 5. The AD Group accounted for the largest percent $(27.3 \%)$ of oral cleanliness scores of 0 and the $\mathrm{CP}$ group accounted for the least (13.8\%), whereas the MR Group accounted for the largest percent (51.2\%) of oral cleanliness scores of 2 and the OTH Group accounted for the least $(30.8 \%)$. Oral cleanliness levels did not vary significantly by disability type ( $P>$.05).

In total, 21 subjects ( 11 male, 10 female) (15.4\%) were found to have no decay. The frequency of no decay did not vary significantly by type of disability $(A D=3, C P=5, D S=4, M R=9,0 T H=0)(P>.05)$.

\section{DISCUSSION}

Oral disease represents a major health problem among individuals with disabilities. ${ }^{3,8,13,14}$ The prevalence and severity of oral disease among this group are higher when compared to the general population. ${ }^{6}$ Poor periodontal health and oral cleanliness have been observed in children with disabilities. ${ }^{15-18}$ These results may be related to the low physical abilities of these individuals and consequent difficulties in tooth brushing. Oral health may be affected by the following: limited understanding on the importance of oral health management, ${ }^{19}$ difficulties in communicating oral health needs, ${ }^{13}$ anticonvulsant medications that impact upon gum health ${ }^{20}$ and a fear of oral health procedures. ${ }^{7}$ Physical restraints and general anesthesia are commonly used to treat adults with disabilities who have fear and communication difficulties related to oral health. ${ }^{21}$ In contrast to individuals without disabilities, who usually manage their own oral health, oral health management of individuals with disabilities often depends on other people, such as parents or employees with assisted living services. ${ }^{6}$

When DMFT indexes were examined with regard to sex, the mean DMFT was found to be higher for females. This is consistent with literature, which has typically found dental caries to exhibit a higher prevalence among females than males. ${ }^{22-25}$

In one previous national population survey, rates of caries among the disabled population were found to be higher in comparison to the general population for all age groups studied. ${ }^{15}$ Not only did children with disabilities tend to have more decayed teeth when compared to children without disabilities, they also had more missing teeth and higher incidences of poor gingival health. ${ }^{15} \mathrm{How}$ ever, there are quite a number of studies examining dmft and DMFT scores of disabled children, and some authors report better dmft and DMFT values among this group than among the general population of children. Shaw et $a^{26}$ reported dmft and DMFT values of 1.36 and 1.85 , respectively, for children with disabilities; Gizani et $\mathrm{al}^{16}$ reported a mean DMFT value of 2.9; and Shyama et $\mathrm{al}^{15}$ reported a mean DMFT of 4.5 for this group. It is most likely that the most significant factor in improving the oral health status of handicapped children is the awareness of their families of importance of oral hygiene habits.

In general, the oral hygiene of the children and young adults examined in the present study was rather poor, with heavy plaque accumulation found in approximately one in three subjects. Data from a study of 12-year-old disabled children in Flanders (Belgium) showed poor oral hygiene in $31.8 \%$ of children, with no significant differences found among disability types. ${ }^{16}$ A study of oral hygiene among mentally retarded female children in Riyadh also showed very poor oral hygiene. ${ }^{17}$ Several other studies have also found poor results for periodontal health and oral cleanliness among children with disabilities. 16,18,27 These results may be due to low physical abilities, which could cause difficulties in tooth brushing among disabled children.

In our study, the frequency of decay among individuals with disabilities was found to be $84.6 \%$. The results of the 1990 Oral Health in Turkey Report, ${ }^{28}$ which utilized the same diagnostic criteria as this study, found the prevalence of caries to be over $90 \%$ among children aged $5-6$ years and approximately $80 \%$ among children 6-12 years. The report also found that dmft and DMFT values increased with age, with a mean DMFT of 4.3 for children and young adults aged 15-19 years - a value higher than that for any of the age groups in our study. There has been a recent study in Turkey by Gökalp et al, ${ }^{29}$ at age 5 , only $30.2 \%$ were caries free and mean dmft was 3.7. Mean DMFT was 1.9 in 12 year-olds and raised 2.3 among 15 year-olds. 
Table 1. Distribution of subjects by age group, sex and type of disability $(n=136)$.

\begin{tabular}{lccccc}
\hline & MR & CP & AD & DS & OTH \\
\hline 2-6 years & 3 & 5 & 5 & 6 & 7 \\
7-12 years & 13 & 10 & 7 & 3 & 8 \\
13+ years & 27 & 14 & 10 & 16 & 26 \\
Total & 43 & 29 & 22 & $4 / 12$ & $21 / 5$ \\
\hline Sex (Male/Female) & $25 / 18$ & $20 / 9$ & $22 / 0$ & 3 \\
\hline
\end{tabular}

Table 2. Distribution of $\mathrm{dmft}$ and DMFT scores by age group and sex.

\begin{tabular}{|c|c|c|c|}
\hline & $2-6$ years $(n=24)$ & $7-12$ years $(n=50)$ & $13+$ years $(n=62)$ \\
\hline \multicolumn{4}{|c|}{ dmft (Mean $\pm S D$ ) } \\
\hline Female & $2.60 \pm 3.71$ & $3.11 \pm 3.26$ & - \\
\hline \multicolumn{4}{|c|}{ DMFT (Mean $\pm S D$ ) } \\
\hline Male & - & $1.32 \pm 3.16$ & $2.60 \pm 2.50$ \\
\hline Female & - & $0.42 \pm 1.02$ & $2.85 \pm 3.72$ \\
\hline Total & - & $0.98 \pm 2.58$ & $2.68 \pm 2.92$ \\
\hline
\end{tabular}

Table 3. Distribution of dmft and DMFT scores by type of disability.

\begin{tabular}{lccccc}
\hline & MR (Mean \pm SD $)$ & CP $($ Mean $\pm S D)$ & AD $($ Mean $\pm S D)$ & DS $($ Mean $\pm S D)$ & OTH (Mean $\pm S D)$ \\
\hline $\mathrm{dmft}$ & $0.70 \pm 1.90$ & $1.03 \pm 1.72$ & $1.09 \pm 1.41$ & $2.43 \pm 3.65$ & $1.46 \pm 1.92$ \\
$\mathrm{DMFT}$ & $2.11 \pm 3.00$ & $1.62 \pm 2.98$ & $0.86 \pm 1.04$ & $0.56 \pm 1.54$ & $1.88 \pm 3.29$ \\
\hline
\end{tabular}

Table 4. Distribution of $\mathrm{dmft}$ and DMFT scores by age group and type of disability.

\begin{tabular}{lccc}
\hline & $2-6$ years & $7-12$ years & $13+$ years \\
\hline dmft (Mean \pm SD) & & & $1.92 \pm 2.87$ \\
MR & $1.66 \pm 2.89$ & $2.30 \pm 2.16$ & $1.71 \pm 1.25$ \\
CP & $1.40 \pm 1.52$ & $4.00 \pm 4.36$ & $1.85 \pm 1.82$ \\
AD & $2.40 \pm 1.52$ & 0.658 & 1.00 \\
DS & $1.83 \pm 3.13$ & & $2.89 \pm 3.33$ \\
OTH & $2.80 \pm 2.49$ & $1.00 \pm 1.91$ & $2.93 \pm 3.83$ \\
P & 0.424 & $0.60 \pm 1.07$ & $1.80 \pm 0.79$ \\
\hline DMFT (Mean \pm SD) & & $0.14 \pm 0.38$ & $3.00 \pm 2.65$ \\
MR & & $0.00 \pm 0.00$ & $2.50 \pm 1.20$ \\
CP & & $2.23 \pm 4.46$ & 0.928 \\
AD & & 0.124 & \\
DS & 1.00 & & \\
OTH & & & \\
P & & & \\
\hline
\end{tabular}

Table 5. Distribution of plaque index scores by type of disability.

\begin{tabular}{|c|c|c|c|c|c|c|}
\hline Plaque Index & MR(\%)* & $\mathrm{CP}(\%)$ & $\mathrm{AD}(\%)$ & DS(\%) & ОTH(\%) & $\mathrm{P}$ \\
\hline 0 & 7 (16.3) & $4(13.8)$ & 6 (27.3) & $4(25.0)$ & $4(15.4)$ & \\
\hline 2 & 22 (51.2) & 13 (44.8) & 9 (40.9) & 5 (31.3) & $8(30.8)$ & \\
\hline
\end{tabular}

* Column percentage

European Journal of Dentistry 


\section{CONCLUSIONS}

We believe in the importance of a preventive approach and the critical role of the dentist in providing proper dental education to parents of individuals with disabilities. In addition, the oral hygiene habits of individuals with disabilities can be improved by close monitoring and periodic dental check-ups.

\section{REFERENCES}

1. Bernier JC. Parental adjustment to a disabled child: a family-system perspective, families in society. Fam Soc 1990;71:589-596.

2. Baykan Z. Causes and prevention of disabilities, handicaps, and defects. J Cont Med Educ 2003;9:336-338.

3. Aytaç S. Increasing importance of rehabilitation of the disabled child. J Dokuz Eylül Univ Soc Sci 2000;2:21-35.

4. Siklos S, Kerns KA. Assessing the diagnostic experiences of a small sample of parents of children with autism spectrum disorders. Res Dev Disabil 2007;28:9-22.

5. Faulks D, Hennequin M. Evaluation of a long-term oral health program by carers of children and adults with intellectual disabilities. Spec Care Dentist 2000;20:199-208.

6. Beange $\mathrm{H}$. Caring for a vulnerable population: Who will take responsibility for those getting a raw deal from the health care system? Med J Aust 1996;164:159-160.

7. Gordon SM, Dionne RA, Snyder J. Dental fear and anxiety as a barrier to accessing oral health care among patients with special health care needs. Spec Care Dentist 1998;18:88-92.

8. Scott A, March L, Stokes ML. A survey of oral health in a population of adults with developmental disabilities: Comparison with a national oral health survey of the general population. Aust Dent J 1998;43:257-261.

9. Cumella S, Ransford N, Lyons J, Burnham H. Needs for oral care among people with intellectual disability not in contact with Community Dental Services. J Intellect Disabil Res 2000;44:45-52.

10. Reichard A, Turnbull HR, Turnbull AP. Perspectives of dentists, families, and case managers on dental care for individuals with developmental disabilities in Kansas. Ment Retard 2001;39:268-285.

11. World Health Organization. Oral Health Surveys: Basic Methods, 4th edn. Geneva: World Health Organization 1997:39-44.

12. Silness J, Löe H. Periodontal disease in pregnancy. II. Correlation between oral hygiene and periodontal condition. Acta Odontol Scand 1964;22:121-135.

13. Faulks D, Hennequin M. Evaluation of a long-term oral health program by carers of children and adults with intellectual disabilities. Spec Care Dentist 2000;20:119-208.
14. Jurek GH, Reid WH. Oral health of institutionalized individuals with mental retardation. Am J Ment Retard 1994;98:656660.

15. Shyama M, Al-Mutawa SA, Morris RE, Sugathan T, Honkala E. Dental caries experience of disabled children and young adults in Kuwait. Community Dent Health 2001;18:181-186.

16. Gizani S, Declerck D, Vinkier F, Martens L, Marks L, Goffin G. Oral health condition of 12-year-old handicapped children in Flanders (Belgium). Community Dent Oral Epidemiol 1997;25:352-357.

17. Al-Qahtani Z, Wyne AH. Caries experience and oral hygiene status of blind, deaf and mentally retarded female children in Riyadh, Saudi Arabia. Odontostomatol Trop 2004;27:37-40.

18. van Houtem CM, de Jongh A, Broers DL, van der Schoof M, Resida GH. Post-academic specialties 9. Dental care of disabled children living at home. Ned Tijdschr Tandheelkd 2007;114:129-133

19. Lindemann R, Zaschel-Grob D, Opp S, Lewis MA, Lewis C. Oral health status of adults from a California regional center for developmental disabilities. Spec Care Dentist $2001 ; 21: 9-14$.

20. Marshall RI, Bartold PM. A clinical review of drug-induced gingival overgrowths. Aust Dent J 1999;44:219-232.

21. Burtner AP, Dicks JL. Providing oral health care to individuals with severe disabilities residing in the community: alternative care delivery systems. Spec Care Dentist 1994;14:188-193.

22. Farsi N. Dental caries in relation to salivary factors in Saudi population groups. J Contemp Dent Pract 2008;9:16-23.

23. Goe LC, Baysac MA, Todd KH, Linton JA. Assessing the prevalence of dental caries among elementary school children in North Korea: a cross-sectional survey in the Kangwon province. Int J Dent Hyg 2005;3:112-116.

24. Zusman SP, Ramon T, Natapov L, Kooby E. Dental health of 12-year-olds in Israel-2002. Community Dent Health 2005;22:175-179.

25. Lukacs JR, Largaespada LL. Explaining sex differences in dental caries prevalence: saliva, hormones, and "life-history" etiologies. Am J Hum Biol 2006; 18:540-555.

26. Shaw L, Maclaurin ET, Foster TD. Dental study of handicapped children attending special schools in Birmingham, UK. Community Dent Oral Epidemiol 1986;14:24-27.

27. Martens L, Marks L, Goffin G, Gizani S, Vinckier F, Declerck D. Oral hygiene in 12-year-old disabled children in Flanders, Belgium, related to manual dexterity. Community Dent Oral Epidemiol 2000;28:73-80.

28. Ertuḡrul F, Elbek-Cubukcu C, Sabah E, Mir S. The oral health status of children undergoing hemodialysis treatment. Turk J Pediatr 2003;45:108-113. 
$\square$ Oral health status of disabled individuals

29. Gökalp S, Doḡan BG, Tekçiçek M, Berberoḡlu A, Ünlüer S.

Bes, on iki ve on bes yas çocukların aḡız dis saḡıḡı profile, Türkiye-2004. Hacettepe Dişhekimliği Fakültesi Dergisi 2007;31:3-10. 